\title{
DIAGNOSTIC AND PREVENTIVE SERVICES IN A NATIONAL INCREMENTAL DENTAL PLAN FOR CHILDREN
}

\author{
Brian A. Burt, BDSc, MPH, PhD*
}

Many observers think that a national dental care plan for children in the United States is a distinct possibility within the foreseeable future. The American Dental Association (ADA), anticipating this possibility, appointed a Task Force in 1969 to “... design the Association's position with respect to participation of the dental profession in national programs concerned with the delivery of health care to the public."l A number of the Task Force's recommendations were adopted by the 1971 House of Delegates ${ }^{1}$ as Association policy for the delivery of dental care in a national program. Some of these policies, which have substantially remained in effect since 1971, are:

(a) Delivery of dental care in a national program should be through the private practitioner in the first instance, with community health centers only encouraged if the supply of private dentists is inadequate.

(b) Priority should be given to the usual, customary, and reasonable (UCR) fee method of payment for practitioners, with fixed fees or table of allowances also recognized as appropriate payment methods. Private third-party carriers rather than government bodies should be encouraged to act as administrative agencies in a national program.

(c) Preventive practices in dentists' offices should be given prime emphasis and first-dollar priority, as should the prevention of dental disease through community measures.

(d) There should be no copayment nor deductible payable by the patient for periodic examinations and diagnosis, prophylaxis, topical applications of fluoride, plaque-control programs, and emergency treatment.

(e) Comprehensive dental care in a national program should begin with an incremental plan ${ }^{\circ}$ for children. ${ }^{2}$

In addition to these policies of the ADA, specific guidelines for dental services for children in dental care programs, either local or national, have been developed by the American Academy of Pedodontics (AAP) and the American Society of Dentistry for Children (ASDC). ${ }^{32}$ These guidelines place high priority on diagnostic and preventive services, with the expectation that peer-review mechanisms will be employed to ensure their adequacy.

Traditionally, diagnostic and preventive services have not been high-fee items. In the past, it was the custom of some dentists to charge a consolidated fee for examination, radiographs, prophylaxis, and oral hygiene advice, whereas others did not charge for these services at all if additional treatment was being

\footnotetext{
-Associate Professor of Dental Public Health, School of Public Health, The University of Michigan, Ann Arbor, Michigan 48109.

- Dunning ${ }^{13}$ defines an incremental plan as:
}

... periodic care so spaced that increments of dental disease are treated at the earliest time consistent with proper diagnosis and operating efficiency, in such a way that there is no accumulation of dental needs beyond the minimum. 
delivered. In more recent years, however, the approach to diagnostic and preventive services has become more sophisticated. Knowledge has expanded, new technics have been introduced, and what may be called a "preventive consciousness" among dentists probably has been raised. In addition, the growth and development of third-party plans in which UCR fees are prefiled by each participating dentist has led to each diagnostic and preventive service's attracting an individual fee. ${ }^{10}$ The result of these developments could be a sharp increase in the cost of what are now perceived as routine diagnostic and preventive services, with perhaps a questionable increase in the benefits they are intended to confer.

This paper uses existing data, ADA policies, and AAP-ASDC guidelines to develop a model of a national incremental dental care plan for children aged 6-13. Its main purpose is to draw attention to the expenditures for diagnostic-preventive services, and how they will influence the total cost of a program which may be administered according to ADA policies. The method used is the application of a model which assesses the per-capita costs of dental care for children moving through the program. As a period of years is involved in the assessment of these costs, Relative Value Units (RVUs) are used as a proxy for dollars. This procedure gets around the problem of fee increases over time.

The model examines separately the per-capita costs for children from fluoridated areas and fluoride-deficient areas. This approach is taken to allow the influence of the diagnostic-preventive costs to be assessed against the proven cost-savings in reparative treatment that result from fluoridation. ${ }^{5}$

\section{The incremental program used in the model}

A national incremental plan for children aged six to 13 would take eight years to reach maturity. All children would be eligible to receive necessary treatment once per year. Services that would be available are those recommended by the AAP-ASDC guidelines, with restrictions based on those used in some thirdparty plans spelled out in areas where the guidelines appeared nonspecific. These are (i) orthodontic care would be restricted to space maintainers and simple interceptive care of up to six months duration, (ii) no gold restorations or restorations in anterior primary teeth would be permitted, and treatment of primary teeth would cease at age 12 , and (iii) while bitewing radiographs would be taken annually as suggested by the AAP-ASDC guidelines, periapical films "... consistent with the needs of the patient" 32 would mean a full series of radiographs no more than once every three years. The model does not consider repair of cleft lip and palate, major oral surgery, and acid-etch procedures. It is assumed that children from fluoridated areas have received full benefits from fluoridation, those from fluoride-deficient areas no benefits. "Specialist care is not included in this model; the orthodontic care described is now frequently delivered by general practitioners.

\section{Method}

A scale of Relative Value Units (RVUs) was developed for quantifying

\footnotetext{
-This situation does not apply in real life; the mobility of the U.S. population ensures that many children receive partial benefits from fluoridation. The distinction is adopted here for practicality.
} 
dental treatment requirements. This scale was taken from the mean fees reported by all general practitioners responding to the Survey of Dental Practice conducted by the Bureau of Economic Research and Statistics, American Dental Association, in $1973 .^{3}$ The scale, shown in Table $I$, uses the fee for a one-surface amalgam restoration in a permanent tooth as unit value. Values for other services are established by dividing the appropriate mean fee from the survey by the mean fee for the one-surface amalgam.

While several methods of epidemiological assessment of dental treatment needs have been suggested,,$^{8,9,24}$ no body of data on dental treatment needs as distinct from disease levels in children could be found. The following steps were therefore required:

(a) determination of disease levels in six-year-old children,

(b) conversion of disease levels to treatment needs in six-year-olds,

(c) determination of disease increments for each year from six to 13 ,

(d) conversion of these increments to treatment needs.

Taking each of these steps in turn:

\section{(a) Disease levels in six-year-old children}

DMF and def data were taken for six year olds in fluoridated ${ }^{5,6,22,35,41,42,45}$ and nonfluoridated $5,7,12,15,20,22,30,41,43,45$ areas. There was naturally some variability in these data, some attributable to real differences between geographic areas, and some to variations in examination conditions and criteria. A simple average of each set was taken, thus giving mean DMF and def values for a hypothetical "national" group of children. (Data from the National Center for Health Statistics were not used here as they do not differentiate between fluoridated and nonfluoridated areas.) By this procedure, six-year-olds from fluoridated areas were estimated to have a mean DMF of 0.17 and a mean def of 2.64 , and those from fluoride-deficient areas a mean DMF of 0.45 and a mean def of 5.05.

\section{(b) Conversion of disease levels to treatment needs in six-year old children}

It was assumed that 80 percent of $\mathrm{DMF}$ and def teeth were decayed teeth requiring treatment. This figure is taken from National Health Survey data, ${ }^{48}$ inflated slightly to allow for the probable delay in seeking treatment among children in the years prior to their entering the program. As a result, six-year-olds from fluoridated areas were estimated to require restorative treatment in 0.14 permanent and 2.11 primary teeth each, while those from fluoride-deficient areas would need restorative treatment in 0.36 permanent and 4.04 primary teeth each.

Studies in Alabama ${ }^{33}$ and Boston ${ }^{34}$ have given the proportional mix of treatment procedures in primary teeth in five-to-six-year-old children. The proportions were fairly similar, despite the geographic differences in study locations; for convenience the Alabama data were used. Although there was naturally some hesitancy in applying treatment-mix data for a rural southern group to a national group, the absence of suitable alternatives made it necessary to do so. Johnson ${ }^{33}$ found that in treating decayed primary teeth in six year olds, 8.78 percent were extracted, 50.17 percent received one-surface amalgams, 30.79 percent received two-surface amalgams, 6.84 percent received three-or-more-surface amalgams, and 3.42 percent received stainless steel crowns. All permanent teeth decayed at 
TABLE I

THE SCALE OF RELATIVE VALUE UNITS (RVUs). UNIT VALUE TAKEN AS THE FEE FOR A ONE-SURFACE AMALGAM IN A PERMANENT TOOTH.

\begin{tabular}{|c|c|c|c|}
\hline TREATMENT SERVICE & RVU & TREATMENT SERVICE & RVU \\
\hline Examination and diagnosis & 0.70 & Stainless steel crown & 3.28 \\
\hline Prophylaxis (child) & 0.94 & Porcelain/metal crown & 13.54 \\
\hline Fluoride (APF) & 0.82 & Post crown & 15.68 \\
\hline Radiographs-full series & 2.14 & Root canal-one canal & 8.66 \\
\hline Radiographs-two bitewings & 0.62 & Root canal-two canals & 11.59 \\
\hline Study cast & 1.00 & Root canal-three canals & 14.75 \\
\hline $\begin{array}{l}\text { Instruction diet/plaque } \\
\text { control }\end{array}$ & 0.82 & Pulpotomy & 1.85 \\
\hline Primary one-surface amalgam & 0.88 & Pulp capping & 0.86 \\
\hline Primary two-surface amalgam & 1.37 & $\begin{array}{l}\text { Gingevectomy (per } \\
\text { quadrant) }\end{array}$ & 6.55 \\
\hline $\begin{array}{l}\text { Primary three-surface } \\
\text { amalgam }\end{array}$ & 1.84 & $\begin{array}{l}\text { Periodontal scaling and } \\
\text { root planing }\end{array}$ & 5.48 \\
\hline $\begin{array}{l}\text { Space maintainer; unilateral } \\
\text { fixed band }\end{array}$ & 3.85 & Three-unit bridge & 48.48 \\
\hline & & Composite, one-surface & 1.29 \\
\hline $\begin{array}{l}\text { Interceptive orthodontics; } \\
\text { removable appliance for } \\
\text { six months }\end{array}$ & 30.27 & Composite, two-surface & 1.84 \\
\hline Extractions & 1.19 & Composite, three-surface & 2.39 \\
\hline $\begin{array}{l}\text { Permanent one-surface } \\
\text { amalgam }\end{array}$ & 1.00 & $\begin{array}{l}\text { Complete upper denture } \\
\text { Complete lower denture }\end{array}$ & $\begin{array}{l}23.98 \\
23.90\end{array}$ \\
\hline $\begin{array}{l}\text { Permanent two-surface } \\
\text { amalgam }\end{array}$ & 1.56 & $\begin{array}{l}\text { Partial denture } \\
\quad \text { (Chrome-cobalt, two clasps) }\end{array}$ & 22.96 \\
\hline $\begin{array}{l}\text { Multisurface pinned } \\
\text { amalgam }\end{array}$ & 2.73 & $\begin{array}{l}\text { Removal of impacted tooth } \\
\text { (Partial-bony impaction) }\end{array}$ & 4.40 \\
\hline
\end{tabular}

Source: American Dental Association, Bureau of Economic Research and Statistics. The 1973 survey of dental practice. Survey of dental fees, 1973. United States, general practitioners. Chicago, American Dental Association, n.d., 5 p. typescript. 
this age were assumed to require one-surface amalgams, while the 4.04 decayed primary teeth per child were assigned treatment needs in the proportions found in Johnson's study.

Other initial treatment needs in the six-year-old group were determined as follows:

(i) every child would require an examination, prophylaxis, topical application of fluoride, full series of radiographs and dietary/plaque control instruction, as suggested in the AAP-ASDC guidelines. ${ }^{32}$

TABLE II

INITIAL TREATMENT NEEDS, EXPRESSED AS AVERAGE NUMBER OF SPECIFIC SERVICES PER CHILD AND RVUS PER SERVICE AND PER CHILD. FOR SIX-YEAR-OLD CHILDREN IN FLUORIDATED AND FLUORIDE-DEFICIENT AREAS.

\begin{tabular}{|c|c|c|c|c|c|}
\hline \multirow[b]{2}{*}{ Service } & \multicolumn{3}{|c|}{ Fluoridated } & \multicolumn{2}{|c|}{ Fluoride-deficient } \\
\hline & RVU & $\mathrm{n} /$ child & RVUs/child & n/child & RVUs/child \\
\hline Examination & 0.70 & 1.00 & 0.70 & 1.00 & 0.70 \\
\hline Prophylaxis & 0.94 & 1.00 & 0.94 & 1.00 & 0.94 \\
\hline Topical fluoride & 0.82 & 1.00 & 0.82 & 1.00 & 0.82 \\
\hline $\begin{array}{l}\text { Radiographs-full } \\
\text { series }\end{array}$ & 2.14 & 1.00 & 2.14 & 1.00 & 2.14 \\
\hline $\begin{array}{l}\text { Dietary/plaque } \\
\text { instruction }\end{array}$ & 0.82 & 1.00 & 0.82 & 1.00 & 0.82 \\
\hline $\begin{array}{l}\text { Permanent one- } \\
\text { surface amalgams } \\
\text { Primary one- }\end{array}$ & 1.00 & 0.14 & 0.14 & 0.36 & 0.36 \\
\hline $\begin{array}{l}\text { surface amalgams } \\
\text { Primary two- }\end{array}$ & 0.88 & 1.06 & 0.93 & 2.03 & 1.79 \\
\hline $\begin{array}{l}\text { surface amalgams } \\
\text { Primary three- }\end{array}$ & 1.37 & 0.65 & 0.89 & 1.24 & 1.70 \\
\hline surface amalgams & 1.84 & 0.14 & 0.26 & 0.28 & 0.52 \\
\hline Stainless steel crowns & 3.28 & 0.07 & 0.23 & 0.14 & 0.46 \\
\hline Extractions & 1.19 & 0.19 & 0.23 & 0.35 & 0.42 \\
\hline Pulpotomies & 1.85 & 0.05 & 0.09 & 0.10 & 0.19 \\
\hline Space maintainers & 3.85 & 0.02 & 0.08 & 0.10 & 0.39 \\
\hline $\begin{array}{l}\text { Interceptive } \\
\text { orthodontics }\end{array}$ & 30.27 & 0.08 & $\underline{2.42}$ & 0.10 & $\underline{3.03}$ \\
\hline $\begin{array}{r}\text { TOTAL } F \\
\mathrm{I} \\
\mathrm{RE} \\
\text { ORT }\end{array}$ & $\begin{array}{l}\text { ENTI } \\
\text { NOSTI } \\
\text { RATIV } \\
\text { ONTIC } \\
\text { TOTA }\end{array}$ & $\begin{array}{l}\text { E AND } \\
\text { C RVUs } \\
\text { RVUs } \\
\text { RVUs } \\
\text { L RVUs }\end{array}$ & $\begin{array}{r}5.42 \\
2.77 \\
2.50 \\
10.69\end{array}$ & & $\begin{array}{r}5.42 \\
5.44 \\
3.42 \\
14.28\end{array}$ \\
\hline
\end{tabular}

'Including extractions and endodontic care

${ }^{2}$ Including space maintainers 
(ii) ten percent of children from fluoride-deficient areas would require a space maintainer, another 10 percent would require interceptive treatment. The corresponding figures for children from fluoridated areas were two percent for a space maintainer, and eight percent for interceptive treatment. These treatment requirements were inferred from published data. ${ }^{4,11,21,23,26,31,38,40,49}$

(iii) ten percent of the fluoride-deficient group, and five percent of the fluoridated group, would require one pulpotomy in a primary molar.

Table II shows per-child requirements, as well as the RVUs needed, for initial treatment of six-year-olds in both fluoridated and fluoride-deficient areas.

(c) Disease increments in children aged six to 13

Estimates of caries increments in permanent teeth were taken from National Health Survey data ${ }^{47,48,50}$ and from control groups in clinical trials held in fluoridated $^{14,25,44}$ and fluoride-deficient ${ }^{17-19,29.46}$ areas. There was a necessary reliance on National Health Survey data in this instance, despite their cross-sectional rather than longitudinal nature because of the limited data from clinical trials. The increment of caries in fluoridated areas was taken to be half of that in fluoridedeficient areas. As all children by definition were receiving annual maintenance care, the effects of regular preventive services were allowed for by reducing these average increments of caries by 35 percent in fluoride-deficient areas ${ }^{28}$ and by 25 percent in fluoridated areas, ${ }^{14,25,44}$ (though it could be argued that results from controlled clinical trials may not be achieved with more widespread use). Table III shows these DMF increments calculated, as well as the total DMFT values at each age.

\section{TABLE III}

\section{AVERAGE PER CHILD DMFT INCREMENTS, AND TOTAL DMFT VALUES, ESTIMATED ${ }^{*}$ FOR AGES SIX TO 13, FOR CHILDREN RECEIVING INCREMENTAL CARE IN FLUORIDATED AND FLUORIDE-DEFICIEN'T AREAS.}

\begin{tabular}{|c|c|c|c|c|}
\hline \multicolumn{3}{|c|}{ Annual DMFT increment per child } & \multicolumn{2}{|c|}{ Total DMFT values per child } \\
\hline Age & Fluoridated & Fluoride-deficient & Fluoridated & Fluoride-deficient \\
\hline 6 & - & - & 0.17 & 0.45 \\
\hline 7 & 0.2 & 0.3 & 0.4 & 0.8 \\
\hline 8 & 0.2 & 0.3 & 0.6 & 1.1 \\
\hline 9 & 0.2 & 0.4 & 0.8 & 1.5 \\
\hline 10 & 0.2 & 0.4 & 1.0 & 1.9 \\
\hline 11 & 0.5 & 0.7 & 1.5 & 2.6 \\
\hline 12 & 0.2 & 0.4 & 1.7 & 3.0 \\
\hline 13 & 0.3 & 0.5 & 2.0 & 3.5 \\
\hline
\end{tabular}

-Data taken from National Health Survey ${ }^{48,50}$ and increments in control groups in clinical trials. ${ }^{14,17-19,25,29,44,46}$ 
(d) Conversion of disease increments to treatment needs in children aged six to 13

In the fluoridated area, children aged seven to nine were estimated to have the whole DMFT increment in one-surface amalgams; those aged 10-13 would have 0.5 percent of the increment in extractions; and, of the rest, 90 percent are one-surface amalgams and 10 percent are two-surface amalgams. ${ }^{16}$ In the fluoridedeficient area, children aged seven to nine were taken to have the whole DMFT increment as one-surface amalgams. The 10-13 year-olds would have 1.0 percent of the DMFT increment as extractions, 48 percent of the remainder as one-surface amalgams and 52 percent as two-surface amalgams. ${ }^{27}$

The Richmond-Woonsocket studies ${ }^{36,37,51,52}$ indicated that incremental needs in the second year were some 40 percent of initial needs. This figure is used here by applying it to needs in the primary dentition in both fluoridated and fluoridedeficient areas. The needs at age seven were taken to be 40 percent of those at age six. Subsequent needs in the primary dentition were based on a similar rate of annual reduction, to allow for the reduced number of untreated decayed teeth in children of this age,,$^{48}$ as well as the effects of dental treatment received in previous years.

Other treatment needs in the seven-to-13 year-old group were determined as follows:

(i) Every child each year would receive an examination, prophylaxis, topical fluoride, and dietary/plaque control instruction, following AAP-ASDC guidelines. A full series of radiographs would be taken every three years, bitewings only in the intervening years.

(ii) Space maintainers at age seven would be required by 2.5 percent of children in fluoride-deficient areas and 1.0 percent in the fluoridated areas. These figures would reduce by 40 percent each year. In both groups, 8.0 percent each year would require interceptive orthodontic treatment from ages seven to nine, diminishing by 40 percent per year after that. These data are estimated from the initial needs given earlier for six year-olds, as no data could be found on the efficacy of interceptive orthodontic treatment in reducing subsequent treatment need.

(iii) No endodontic treatment should be necessary for either group from age seven to 11 as all are receiving regular maintenance care. Pulpal exposure following traumatic injury in this group would be given temporary treatment until the child grew older. In both groups, 5.0 percent of 12-13 year olds would require a one-canal anterior root filling as a result of trauma.

The estimates of annual incremental treatment needs are given in Table 4, for children from fluoridated areas, and in Table 5 for those from fluoride-deficient areas.

\section{Results}

Results are shown in Table 6, which presents the cumulative RVUs received by a child, in either a fluoridated or a nonfluoridated area, as he or she moves through the program. The difference in restorative RVUs received is 49.8 percent less for a child from the fluoridated area, much as would be expected. When orthodontic RVUs are added, the difference in total RVUs drops to 27.6 percent. When total care received is considered, the difference in RVUs received drops 


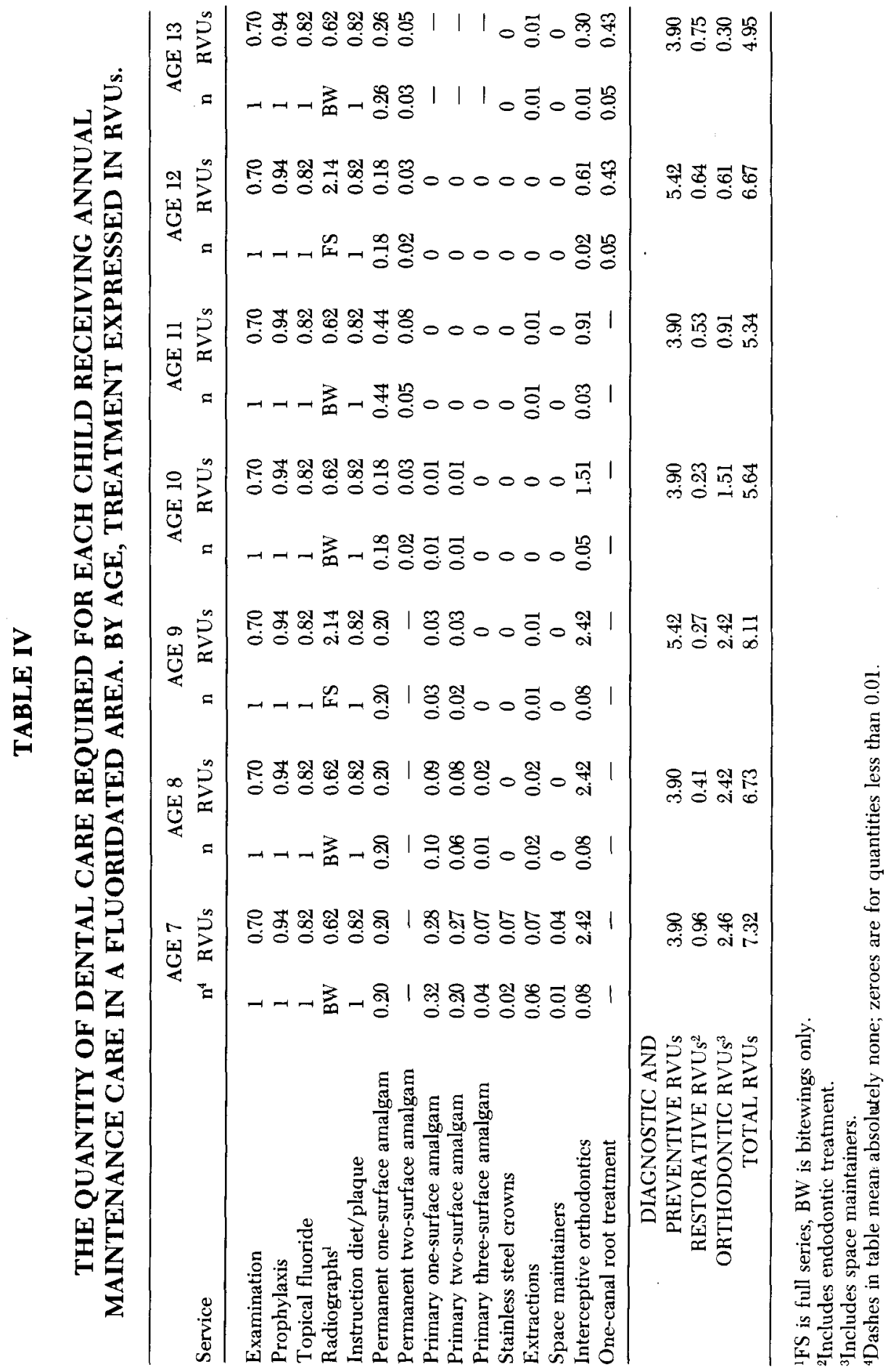




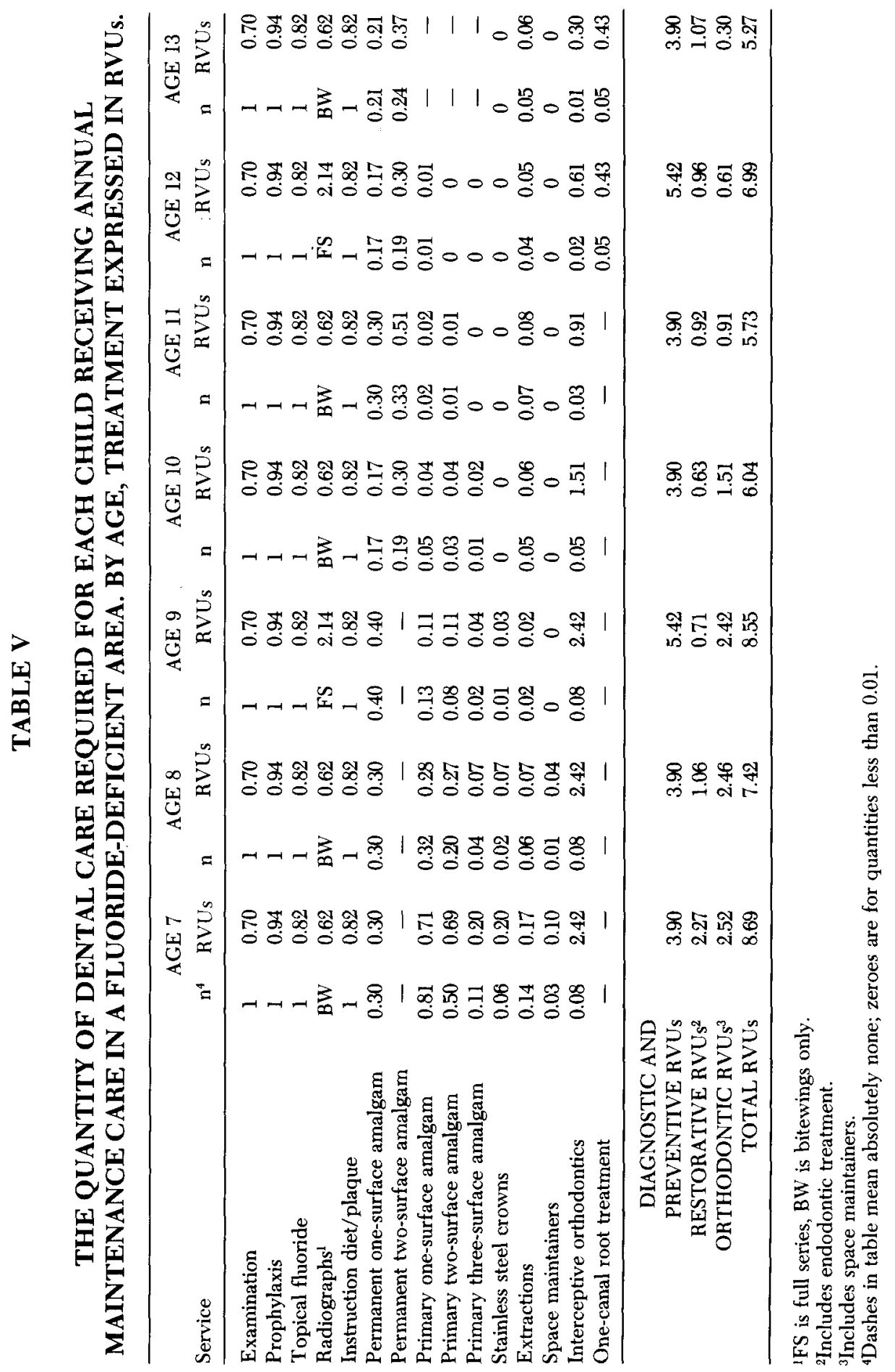




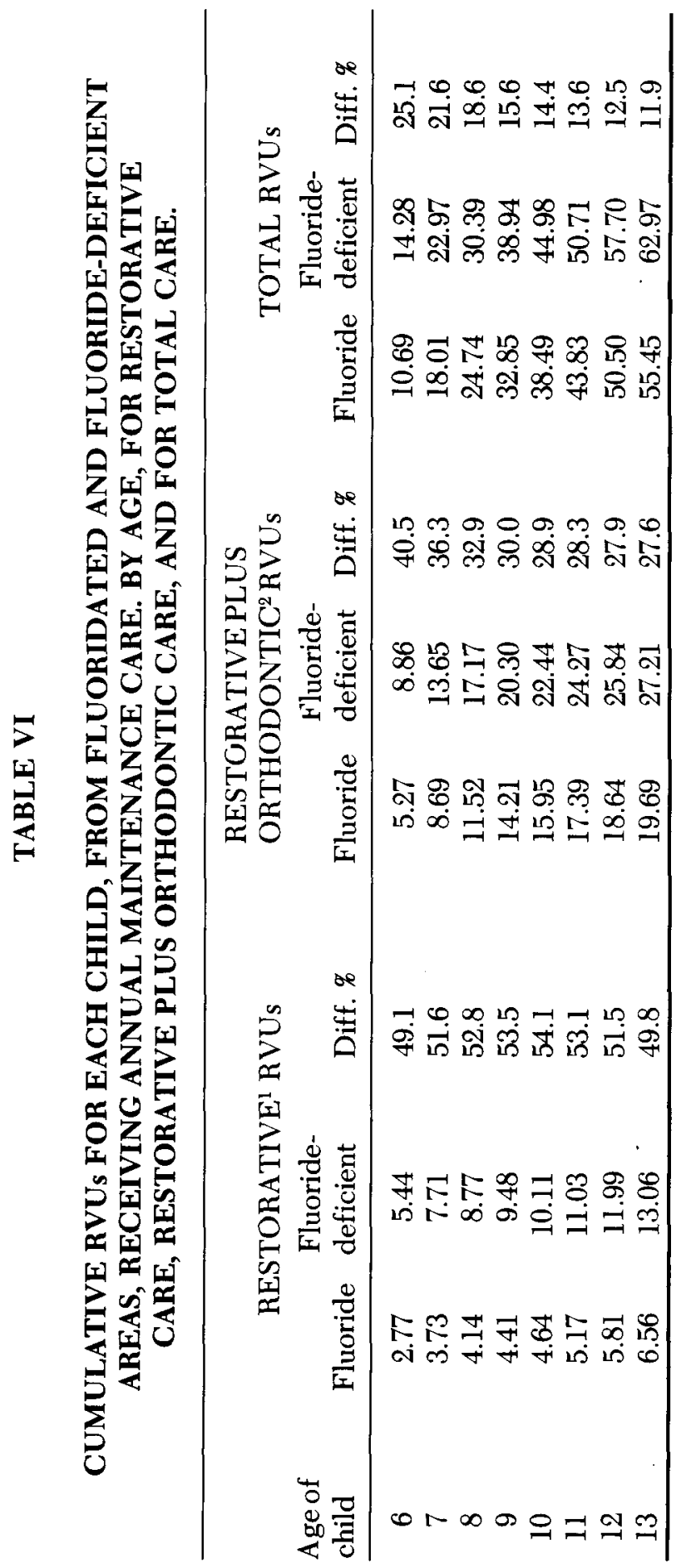

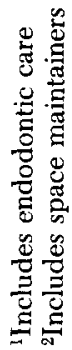


to only 11.9 percent less for the child from a fluoridated area. Even if orthodontic care is excluded, the difference in RVUs received is only 13.3 percent for the child from a fluoridated area. Over the eight years a child would be in the program, diagnostic-preventive services constitute 64.5 percent of the total cost of his dental care in a fluoridated area, and 56.8 percent of total costs in a fluoridedeficient area.

\section{Discussion}

Before discussing the implications of these results, some consideration of the methods used to achieve them is in order. An exercise of this nature highlights the gaps in the knowledge of disease progression and the extent of treatment delivered; numerous assumptions on treatment needs were therefore required. Some assumptions are more critical than others. For example, even radical alterations in the frequency of low-RVU services, or of moderate-RVU services of low frequency, will not make much difference in the results obtained. To be specific, the effects on costs of increasing the frequency of pulpotomies (Table II) by as much as five times are slight, and about equal the effects of trebling the frequency of stainless steel crowns. Marked alterations can also be made in the frequency and proportions of amalgam restorations without much effect on the absolute or relative costs of the program.

The most sensitive assumptions on treatment needs in this model concern orthodontics. The high relative value of interceptive orthodontic care means that only moderate changes in the estimates of orthodontic treatment required could have a pronounced effect on the results of the study. In econometric terms, the model is "sensitive" to the extent of orthodontic care required by the study populations. Quantification of orthodontic treatment need is notoriously subjective. ${ }^{11,21}$ Rather than having to use "guesstimates" in exercises like this one, it would be better to obtain data on the extent of interceptive orthodontic care actually being delivered. Such data could probably be found now in the records of dental prepayment carriers. Their publication, even allowing for the fact that they apply only to certain population groups in certain areas, would be a useful addition to the dental literature. The same thinking applies to other high-RVU items that are difficult to quantify, for example root canal treatments.

The results of this exercise highlight two features that merit discussion. These are (i) the high proportion of total per-capita expenditures for diagnostic-preventive services and (ii) the way in which expenditures on diagnostic-preventive services can erode the cost-savings due to fluoridation. Diagnostic-preventive services considered in this study are the first five services listed in Tables IV and $V$, though this list could be seen as conservative by some proponents of the preventive philosophy ${ }^{39}$ (or excessively liberal by others).

It must be reemphasized at this point that sound diagnosis is fundamental if the care delivered is to be of acceptable quality. It must also be made clear that any national program, or even a local third-party program for that matter, should be based on a long-term preventive approach. Once these commitments are made, it must still be asked whether the expenditure on these diagnostic-preventive services is money well spent. The question is one of cost-effectiveness; can the same degree of dental health be achieved for children in a national program with less expenditure? 
Recent developments have led to the emergence of what can be called the "diagnostic-preventive package." The implication is that a standard set of diagnostic and preventive services may be being delivered indiscriminately, and perhaps.inappropriately in many cases, rather than particular services chosen to meet the needs of the individual patient. Several factors which have led to the development of routine "packages" can be identified; they include the ready availability of well-advertised products, and fairly simple technical procedures. Perhaps more important, it is the way in which much third-party dentistry is administered. A participating dentist who prefiles his fees submits an individual fee for examination, prophylaxis, topical application of fluoride, radiographs, study casts, sometimes dietary counselling, oral hygiene instruction, and caries susceptibility tests. The sum of these individual fees can be considerable. In addition, many third-party plans encourage the use of diagnostic-preventive services by setting low patient copayments for them, or none at all. The rationale for this approach is to encourage patients to use dental services regularly and to raise the quality of care above that of "drill-and-fill," both entirely laudable aims. But routinely delivered "packages" may be an unforeseen and undesirable side-effect of low copayments for diagnostic and preventive services.

The recommendations of the specialist groups in dentistry for children have also inadvertently helped to foster "packages." The guidelines for third-party dental programs for children, produced by the American Academy of Pedodontics and the American Society of Dentistry for Children, ${ }^{32}$ and used in this study, are intended to lead to the highest possible quality of care for the individual patient. It can be argued, however, that "optimum" quality of individual patient care is incompatible with the goals of a third-party program; some restrictions must be placed on services and their frequency of use in order to keep costs within reasonable limits. Dentists are trained to provide their patients with "the best," limited only by the patients' ability or willingness to pay. The reduction of the out-ofpocket cost barrier brought on by third-party payment, government or private, leads some dentists to believe that now all covered patients should receive "the best." Sometimes it is difficult to realize that a program's financial resources are finite, just as a private patient's are, and that some limitations on services and their frequency are necessary if a program is to achieve its aims.

The results of this study spotlight several areas where the recommendations in the guidelines ${ }^{32}$ can be questioned. One such area concerns radiographs. The guidelines state that radiographs for recall patients should consist of “. . . cavitydetecting radiographs at least annually, and periapical films consistent with the needs of the patient." 32 Many question the necessity for this frequency of bitewing radiographic exposure, especially for children on annual recall, and most especially for those receiving fluoridated water. The hazards of unnecessary radiation must also be taken into account when considering the frequency of radiographic exposure for the individual. In third-party programs, periapical films "... consistent with the needs of the patient" is too vague. Some specific frequency is required, though always with the proviso that the truly unusual patient with special requirements must be protected.

Another area of concern in the guidelines ${ }^{32}$ concerns topical applications of fluoride. Recall patients are advised to receive “... topical applications of 
fluorides at least annually," regardless of whether they have consumed fluoridated water all their lives or not. While there is evidence to show that topical applications give some added benefit to children in fluoridated areas, ${ }^{14,25,44}$ the cost-benefits of such a procedure must be questioned.

The results of this study, without being conclusive, indicate that some rational approach must be made toward controlling the cost of diagnostic-preventive services in third-party programs. While it is clear that the private practitioner must be included in any national program for children, it is hard to see that the system of prefiled fees, at least for diagnostic and preventive services, would be accepted, even if private carriers administered the program. What is required is a method of encouraging the appropriate delivery of diagnostic and preventive procedures in a cost-effective manner, while still protecting the patient with unusual needs.

The problem of diagnostic-preventive costs discussed in this study is best treated by the appropriate groups within organized dentistry. Current policies are so worded that sweeping change would not be required. ADA Resolution 27-1971-H, ${ }^{1}$ for example, states that various methods of reimbursement are to be encouraged in a national program, with the mandating of capitation as the only method to be discouraged. In the guidelines for dentistry for children, this statement is made:

... it may be useful to request participating dentists to present a description of the "normal package" of preventive and educational services provided as a routine part of the treatment of children in their office. ${ }^{32}$

An examination of both these statements indicates that a capitation approach might be developed for diagnostic and preventive services, despite the distaste for capitation among most dentists. Both the fee and the list of services covered could be determined for different areas, and for patients of different ages. Those patients who required extra preventive services would most likely be balanced by those who required minimal attention, especially among recall patients and most especially in fluoridated areas. This approach would also allow standards for radiographs, fluoride applications, and perhaps other services to be developed for different areas. The truly unusual patient could be catered for adequately by preauthorization procedures. Fee-for-service could be retained for restorative treatment. The imposition of patient copayments for diagnostic-preventive services may be a simpler method of controlling "front-end" costs, but many would view this move as retrograde and unimaginative. The capitation approach merits serious consideration.

Unless some definite move toward controlling diagnostic-preventive costs is made by dentistry, itself, less rational controls may be introduced from other sources. Perhaps of most concern, the uncontrolled ballooning of "front-end" costs will erode the savings that should come with fluoridation, and that would be nothing less than tragic.

\section{Summary}

A modelling exercise was carried out to examine the potential expenditure in a national incremental dental program for children aged six to 13 . Using Relative Value Units (RVUs) as a proxy for dollars, the relative expenditures for care 
per child in fluoridated and fluoride-deficient areas were assessed. Dental treatment requirements were taken from existing data as far as possible. Arrangements for the delivery of care were based on existing policies of the American Dental Association, and services delivered were based on the recommendations of the American Academy of Pedodontics and the American Society of Dentistry for Children. Orthodontic care was limited to space maintainers and simple interceptive care. Children were assumed to receive initial care at age six, and annual maintenance care from ages seven to 13 .

The results showed that although restorative care would be 49.8 percent less expensive for children in fluoridated areas, total care would be only 11.9 percent less expensive. The major reason for this difference was the high proportion of annual maintenance-care costs that would be absorbed by diagnostic and preventive services using UCR fees. The necessity for much of this care is questioned under the conditions of this model, and some methods by which the dental profession might control the relatively high cost of diagnostic-preventive services are suggested.

\section{Acknowledgments}

This study was partly supported by PHS contract number NO1-DH-44101. The assistance of Paul J. Loos, DDS, MS, is gratefully acknowledged.

\section{REFERENCES}

1. American Dental Association. Dentistry in national health programs; reports of the Special Committees to the Task Force on national health programs. Chicago, the Association, c1971. $96 \mathrm{p}$. (p. 4).

2. American Dental Association. Guidelines for dentistry's position in a national health program. Am. Dent. A. J., 83:1226-32, Dec. 1971.

3. American Dental Association, Bureau of Economic Research and Statistics. The 1973 survey of dental practice. Survey of dental fees, 1973. United States, general practitioners. Chicago, American Dental Association, n.d. 5 p. typescript.

4. Ast. D. B., Allaway, Norman, and Draker, H. L. The prevalence of malocclusion related to dental caries and lost first permanent molars, in a fluoridated city and a fluoride-deficient city. Am. J. Orthodont., 48:106-13, Feb. 1962.

5. Ast, D. B., et al. Time and cost factors to provide regular periodic dental care for children in a fluoridated and nonfluoridated area: final report. Am. Dent. A. J., 80:770-6, Apr. 1970.

6. Bell, C. D. A look at the dental health of school children in Richmond, Indiana. Ind. Dent. A. J., 51:261-3, June-July 1972.

7. Creighton, W. E. Dental caries experience of Negro and Caucasian children in Portland, Oregon. J. Dent. Child., 36:139-43, Mar.-Apr. 1969.

8. Davies, G. N., Horowitz, H. S., and Wade, W. The assessment of dental caries for public health purposes. Community Dent. Oral Epidemiol., 1:69-73, 1973.

9. $\ldots$. The assessment of periodontal disease for public health purposes. J. Periodont. Res., 9:62-70, 1974.

10. Delta Dental Plans of Michigan. Personal communication. March, 1975.

11. Draker, H. L. Judgments of peers in assessing the orthodontic handicap. J. Pub. Health Dent., 30:134-40, Summer 1970 .

12. Dudney, G. G., et al. A pre-fluoridation survey in Asheville, North Carolina. N. C. Dent. Soc. J., 52:12-6, Aug. 1969.

13. Dunning, J. M. Principles of dental public health. 2nd ed. Cambridge, Mass., Harvard University Press, 1970. xiv + 598 p.

14. Englander, H. R., et al. Incremental rates of dental caries after repeated topical sodium fluoride applications in children with lifelong consumption of fluoridated water. Am. Den. A. J., 82:354-8, Feb. 1971.

15. Friedman, L. A., et al. Dental survey of Houston Catholic parochial school children. Tex. Dent. J., 89:16-21, Nov. 1971. 
16. Graves, R. C., and Burt, B. A. The pattern of the carious attack in children as a consideration in the use of fissure sealants. J. Prev. Dent., 2:28-32, May-June 1975.

17. Heifetz, S. B., Horowitz, H. S., and Driscoll, W. S. Two-year evaluation of a self-administered procedure for the topical application of acidulated phosphate-fluoride; final report. J. Pub. Health Dent., 30:7-12, Winter 1970.

18. Heifetz, S. B., Driscoll, W. S., and Creighton, W. E. The effect on dental caries of weekly rinsing with a neutral sodium fluoride or an acidulated phosphate-fluoride mouthwash. Am. Dent. A. J., 87:364-8, Aug. 1973.

19. Heifetz, S. B., and Horowitz, H. S. Effect of school water fluoridation on dental caries: interim results in Seagrove, N. C., after four years. Am. Dent. A. J., 88:352-5, Feb. 1974.

20. Heise, A. L., et al. Meeting the dental treatment needs of indigent rural children. Health Serv. Rep., 88:591-600, Aug.-Sept. 1973.

21. Helm, Sven, et al. Estimates of orthodontic treatment need in Danish schoolchildren. Community Dent. Oral Epidemiol., 3:136-42, 1975.

22. Hill, I. N., Blayney, J. R., and Wolf, W. The Evanston dental caries study. XVI. Reduction in dental caries attack rates in children six to eight years old. Am. Dent. A. J., 53:327-33, Sept. 1956.

23. . The Evanston dental caries study. XIX. Prevalence of malocclusion of children in a fluoridated and control area. J. Dent. Res., 38:782-94, July-Aug. 1959.

24. Hobdell, M. H., Burt, B. A., and Longhurst, Peter. A method of planning a dental treatment programme for an institutionalized population. Community Dent. Oral Epidemiol., 3:166-73, Aug. 1975.

25. Horowitz, H. S., and Heifetz, S. B. Evaluation of topical applications of stannous fluoride to teeth of children born and reared in a fluoridated community: final report. J. Dent. Child., 36:355-61, Sept,-Oct. 1969.

26. Horowitz, H. S., and Doyle, Joe. Occlusal relations in children born and reared in an optimally fluoridated community. II. Clinical findings. Angle Orthodont., 40:104-11, Apr. 1970.

27. The effect on dental caries of topically-applied acidulated phosphate-fluoride: results after three years. Am. Dent. A. J., 82:359-65, Feb. 1971.

28. Horowitz, H. S. Fluoride: research on clinical and public health applications. Am. Dent. A. J., 87: 1013-8, Oct. 1973

29. Horowitz, H. S., and Kau, M. C. Retained anticaries protection from topically applied acidulated phosphate-fluoride 30- and 36-month posttreatment effects. J. Prev. Dent., 1:22-27, May-June 1974.

30. Infante, P. F., and Owen, G. M. Dental caries and levels of treatment for school children by geographic region, socioeconomic status, race, and size of community. J. Pub. Health Dent., 35:1927 , Winter 1975 .

31. Jago, J. D. The epidemiology of dental occlusion; a critical appraisal. J. Pub. Health Dent., 34:8093, Spring 1974.

32. Johnson, B. E., and Young, W. O., eds. Manual for children's dental care programs. 2nd ed. Chicago, American Academy Pedodontics and American Society Dentistry Children. $1974.55 \mathrm{p}$.

33. Johnson, J. E. Initial incremental dental care for the Leeds Primary School. J. Pub. Health Dent., 31:191-7, Summer 1971.

34. Jong, Anthony, and Leverett, D. H. The operation of a community dental clinic in a health center: an evaluation. J. Pub. Health Dent., 31:27-31, Winter 1971.

35. Jordan, W. A. Fluoridated water benefits continue: Albert Lea's 1969 dental survey. Northwest Dent., 49:77-80, Jan.-Feb. 1970.

36. Law, F. E., Johnson, C. E., and Knutson, J. W. Studies on dental care services for school children, first and second treatment series, Woonsocket, R. I. Pub. Health Rep., 68:1192-8, Nov. 1953.

37. Studies on dental care services for school children; third and fourth treatment series, Woonsocket, R. I. Pub. Health Rep., 70:402-9, Apr. 1955.

38. Moller, Palmi. Dentofacial deformities: malocclusion. p. 72-93. (In Pelton, W. J., et al. The epidemiology of oral health. Cambridge, Mass., Harvard University Press, xix +167 p.).

39. Nizel, A. E. How to deliver a comprehensive preventive dentistry service that dental insurance carriers can underwrite. Am. Dent. A. J., 92:911-29, May 1976.

40. Popovich, Frank, and Thompson, G. W. A longitudinal comparison of the orthodontic treatment priority index and the subjective appraisal of the orthodontist. J. Pub. Health Dent., 31:2-8, Winter 1971.

41. Russell, A. L., and White, C. B. Dental caries in Maryland children after seven years of fluoridation. Pub. Health Rep., 76:1987-93, Dec. 1961.

42. Soricelli, D. A. Personal communication. March 1975.

43. Summers, C. J. Dental needs and prevalence of dental caries in Wayne County grade school children. Mich. Dent. A. J, 52:127-35, May 1970.

44. Szwejda, L. F. Fluorides in community programs: a study of four years of various fluorides applied 
topically to the teeth of children in fluoridated communities. J. Pub. Health Dent., 32:25-33, Winter 1972.

45. Tank, Gertrude, and Storvick, Clara A. Caries experience of children one to six years old in two Oregon communities (Corvallis and Albany). 1. Effect of fluoride on caries experience and eruption of teeth. Am. Dent. A. J., 69:749-57, Dec. 1964.

46. Trubman, Aaron, and Crellin, J. A. Effect on dental caries of self-application of acidulated phosphate fluoride paste and gel. Am. Dent. A. J., 86:153-7, Jan. 1973.

47. U. S. Public Health Service, National Center for Health Statistics. Decayed, missing, and filled teeth in adults, United States - 1960-62, by Kelly, J. E., Van Kirk, L. E., and Garst, Caroline C. PHS Publ. No. 100-Ser. 11-No. 23, Washington, Government Printing Office, 1967. 47 p.

48. . Decayed, missing, and filled teeth among children, United States, by Kelly, J. E., and Scanlon, J. V. DHEW Publ. No. (HSM) 72-1003-Ser. 11-No. 106, Washington, Government Printing Office, 1971. 47 p.

49. An assessment of the occlusion of the teeth of children 6-11 years, United States, by Kelly, J. E., Sanchez, Marcus, and Van Kirk, L. E. DHEW Publ. NO. (HRA) 74-1612-Ser. 11No. 130, Washington, Government Printing Office, 1973. vi +52 p.

50. by Kelly, J. E., and Harvey, Clair R. DHEW Publ. No. (HRA) 75-1626-Ser. 11-No. 144, Washington, Government Printing Office, 1974. iii +34 p.

51. Waterman, G. E., and Knutson, J. W. Studies on dental care services for school children; first and second treatment series, Richmond, Indiana. Pub. Health Rep., 68:583-9, June 1953.

52. Studies on dental care services for school children; third and fourth treatment series, Richmond, Indiana. Pub. Health Rep., 69:247-54, Mar. 1954.

\section{Community Health}

From time immemorial communities have organized themselves with varying degrees of sophistication to provide for the promotion of health and the prevention and treatment of diseases and disability, and to ensure the well-being of individuals as well as of the community as a whole. The extent to which they succeeded in their endeavors depended on the extent to which the services provided were within the reach of the majority of the population in a form that they could accept and use. This in turn depended on the extent to which the professional cadres responsible for the services were able and willing to deal with the most serious prevailing diseases, deficiencies, and harmful environmental conditions in a manner that could be understood by the people and that fitted in with their own attitudes and beliefs.

-W. H.O. Geneva, Vol. 30, January 1976

\section{Oral Health in Jefferson County}

Dr. Polly Ayers reports Jefferson County's (Alabama) fiftieth anniversary of the Dental Bureau that she now directs. In 1975, about 50 members are recognized as the staff. They include dentists, hygienists, assistants, an equipment mechanic, clerk for dental stores, eligibility clerk, and clerical personnel, who provide oral health services in five health centers and two large mobile clinics. Because the citizens of Birmingham have been unable to get its water fluoridated to date, the staff last year completed 21,832 restorations, 2,996 extractions, 3,928 treatments with fluoride, and a tremendous educational effort.

\section{-Abstracted from Annual Report of Jefferson County Health Department}

